CROCE, Marcela (Dir.). Historia comparada de las literaturas argentina y brasileña. Tomo I: De la colonia a la organización nacional (1808-1845). Villa María: Eduvin, 2016.

\title{
Eduardo Coutinho
}

Universidade Federal do Rio de Janeiro/CNPq

Rio de Janeiro - RJ

Embora as relaçóes entre o Brasil e os países hispano-americanos estejam constituindo cada vez mais objeto de estudo, em especial nos planos econômico, social e político, essas relaçóes ainda são muito tímidas no que diz respeito à esfera da cultura, e, mais particularmente, da produçáo literária. Sente-se falta de textos que abordem mais de perto a literatura brasileira e a dos diversos países hispano-americanos, focalizando, por uma perspectiva comparatista, suas semelhanças e diferenças, de modo a estabelecer-se um verdadeiro diálogo entre essas vozes. Têm surgido, nas últimas décadas, histórias literárias voltadas para a América Latina como um todo, que deixaram clara, pelo próprio uso do termo, sua preocupação em incluir o Brasil no conjunto - citem-se aqui as belíssimas séries Palavra, literatura e cultura (1993), organizada por Ana Pizarro, e Literary Cultures of Latin America: A Comparative History (2004), coordenada por Mario Valdés e Djelal Kadir. E lembre-se que, já na década de 1940 (mais precisamente em 1945), Heríquez Ureña expressou essa preocupação ao publicar a sua Corrientes literarias de América Latina, que incluía o Brasil. No entanto, o que prevalece em todas essas histórias é a noção mais ampla de "continente", recorte adotado que não só justifica, como requer a referida inclusão.

É verdade que o conceito de "nação", identificado a "estado-nação", é hoje um conceito que não mais se sustenta do ponto de vista ontológico, como quiseram os adeptos do Iluminismo, mas que ainda tem uma existência sólida como construçáo discursiva e que se acha presente na maioria das instâncias da vida contemporânea, desde a configuração política dos países no contexto internacional, até os aspectos mais banais da vida cotidiana, como as competiçóes desportivas e as festas que celebram aspectos que se dizem próprios da cultura de um povo. A nação política como construção calcada em interesses específicos do grupo que a constituiu continua atuando como referência nos discursos em voga nas mais variadas áreas do conhecimento, e o conceito segue desempenhando um papel crucial no panorama internacional. $\mathrm{Na}$ História, e mais especificamente na História Cultural e Literária, ele é muitas vezes complementado por outros conceitos, como o de "região cultural", mas não é em momento algum abandonado. A "nação" permanece no contexto 
internacional como um conjunto que difere de outros por singularidades que, embora provisórias e plurais, atuam como marcas de diferenças. E são esses traços que, mesmo em sua variedade e provisoriedade, devem ser estudados ao abordar-se a produção de um país.

A Historia comparada de las literaturas argentina y brasileña, que Marcela Croce organizou, e para a qual contribuiu também com a redação de diversos capítulos, sozinha ou em colaboração com outro estudioso da questão, é, nesse sentido, uma contribuição extraordinária e pioneira para o estudo da produção literária dos dois países. O Brasil e a Argentina são duas naçóes geograficamente vizinhas, que passaram por processos de colonização semelhantes, mas com diferenças também importantes, que obtiveram a independência política mais ou menos numa mesma época, mas continuaram dependentes do ponto de vista cultural e econômico, e que chegaram à modernidade com uma série de aspectos que as aproximam e, ao mesmo tempo, as distanciam. Essas semelhanças e diferenças em seu processo de constituição são o objeto de estudo dessa história literária que, entre seus muitos méritos, busca romper a barreira que infelizmente ainda perdura entre os dois países, e para a qual contribuiu inegavelmente a diferença idiomática, sobretudo quando comparamos com o que ocorreu entre os diversos países da América Hispânica.

$\mathrm{Na}$ estruturação do volume, que é, aliás, o primeiro de uma série de seis, a organizadora e seus colaboradores optaram por uma metodologia comparatista perfeitamente adequada ao diálogo que pretendiam estabelecer: a relação de semelhanças e diferenças entre as produçóes dos dois contextos. Foi feita uma seleção de textos literários que contribuíram para a formação de cada nação, e de pontos de encontros e desencontros na história cultural dos dois países, e construiu-se um contraponto rico e instigante, sempre baseado em fatores históricos concretos, que deu origem a uma discussáo bastante frutífera entre vozes nem sempre pensadas pelo que tinham em comum, como é o caso de Hidalgo, Ascasubi e Hernández, de um lado, e de Fagundes Varela, de outro, ou de José Bonifácio de Andrada e Silva e Juan María Gutiérrez, os dois últimos lidos pelo autor do capítulo como intelectuais orgânicos na terminologia de Gramsci. Observe-se, contudo, que em todos esses casos foi levada em conta a relação entre os aspectos culturais e histórico-políticos, evitando-se sempre qualquer tipo de arbitrariedade nas aproximaçóes estabelecidas.

O fato de tratar-se de uma história literária que tem como objeto dois países da América Latina já constitui por si só uma grande inovação, na medida em que se rompe com o modelo tradicional desses estudos, quase sempre voltados para a fórmula Europa/América do Norte x América Latina, em prol de um comparatismo intra-americano, mas o mais relevante, no caso, é o abandono da perspectiva hierarquizadora, presente, por exemplo, nos estudos 
de fontes e influências, e sua substituição por uma visão crítica apurada em que póe por terra qualquer sentido de superioridade ou inferioridade de um dos termos da comparação, adotando-se, em seu lugar, um tratamento em pé de igualdade. Não se trata, nas palavras da organizadora, de "avaliarem-se inovaçôes nem de se estabelecerem prioridades no tempo, mas de se mostrarem as variantes que alguns modelos externos adquirem em cada país". É assim que o Indianismo brasileiro de um Gonçalves Dias, que idealiza o índio, é confrontado com o Romantismo argentino, que o aborda como um sujeito sem identidade; ou o mito rural na poesia gauchesca, no qual o tipo regional adquire voz, que é estudado lado a lado à figura do negro no século XIX brasileiro, visto antes como objeto do que como sujeito.

Sem nenhuma pretensão de construir-se uma história literária de caráter totalizador, o recorte adotado pela organizadora toma como ponto de partida um momento que considera fundamental na história dos dois países - a recepçáo local da Revolução Francesa e suas consequências mais representativas, que têm como corolário a constituição das pátrias argentina e brasileira. A partir daí, são traçados paralelos que nem sempre correspondem a uma cronologia rígida e nem a uma equivalência exata no que concerne ao objeto - autores ou obras, por exemplo, são, por vezes, comparados a movimentos literários -, mas esse aspecto, longe de constituir problema, revela, ao contrário, a flexibilidade do método comparatista e a riqueza que este método permite na abordagem do fenômeno. Daí a forma de ensaio que a história literária apresenta, mas de um ensaio que não deixa jamais de lado a dimensão histórica, instituindo-se antes como um conjunto orgânico, uma produção sistemática cuja articulação fica assegurada, nas palavras da própria organizadora, "pela avaliação e relevância que os fatos adquirem nos textos e a maneira com que logram articular-se em uma construção discursiva”.

Eduardo F. Coutinho. Doutor pela Univ. Califórnia (Berkeley, EUA). É Professor Titular de Literatura Comparada da UFRJ e pesquisador I A do CNPq. Tem sido Professor Visitante em diversas universidades no Brasil e no exterior. É membro fundador e ex-presidente da ABRALIC, Vice-Presidente da AILC (Associação Internacional de Literatura Comparada) e consultor científico de diversas agências de fomento à Educação. Publicou grande número de ensaios em revistas e periódicos especializados do Brasil e do exterior e é autor e organizador de diversos livros, dentre os quais The Synthesis Novel in Latin América: a Study of J. G. Rosa's Grande sertão: veredas (1991), Em busca da terceira margem: ensaios sobre o Grande sertấo: veredas (1993), Literatura Comparada na América Latina: ensaios (2003), publicado também em espanhol (Colômbia, 2003), e Literatura Comparada: reflexóes (2013).

E-mail: eduardocoutinho17@gmail.com 